\title{
Perspectivas do uso do controle biológico contra doenças florestais
}

\author{
Albino Grigoletti Júnior \\ Álvaro Figueredo dos Santos \\ Celso Garcia Auer
}

\section{RESUMO}

Produtos químicos têm sido usados na agricultura para proteção contra patógenos. Entretanto, seus efeitos nocivos têm estimulado a redução de seu uso e a adoção de métodos naturais menos agressivos. Os principais efeitos indesejáveis do uso de agroquímicos são a poluição ambiental, a intoxicação do homem e animais e o surgimento de resistência dos patógenos a estes produtos. $\mathrm{O}$ controle biológico vem ao encontro desta demanda, pois se baseia em métodos ambientalmente corretos e que podem fazer parte de um controle integrado de doenças. A utilização do controle biológico na área florestal é possível, principalmente em viveiros, onde as condições ambientais podem ser controladas. No campo, a sua utilização é adequada para o controle de patógenos radiculares e também, pode ser utilizado para a preservação de madeiras, evitando a ação de agentes manchadores.

Palavras-chave: antagonistas, biocontrole, patógenos.

\section{ABSTRACT}

PERSPECTIVES ON BIOLOGICAL CONTROL AGAINST FOREST DISEASES.Chemical products have been used to protect crops in agriculture, however, theirs harmful effect, have been incited their reduction and the use of natural control methods. The main harmful effects of their use are environment pollution, man toxicity and microorganisms resistance. Biological control attend this request, because is based on environment correct methods that may compose the Integrated Disease Control. The use of forest biological control may be used on nurseries, where environment conditions may be controlled, on field to control soil pathogens and also to protect woods against stain agents.

Key words: antagonists, biocontrol, pathogens. 


\section{INTRODUÇÃO}

O conceito de controle de doenças mudou nas últimas décadas. Anteriormente, o objetivo era eliminar completamente o patógeno com o uso indiscriminado e contínuo de produtos químicos sem medir as conseqüências. Este procedimento provocou alterações no ambiente, como a seleção de patógenos resistentes, ocorrência de surtos de doenças consideradas como secundárias, diminuição de microrganismos benéficos, além de causar efeitos deletérios (nocivos) ao homem, aos animais e ao ambiente, através do acúmulo de resíduos no solo, na água e nos alimentos.

Há tempos, os pesticidas químicos tem sido usados na agricultura, entretanto, seus efeitos colaterais têm estimulado a redução de seu uso e a adoção de métodos naturais menos agressivos. De acordo com LISANSKI \& COOMBS (1994) citados por MELO \& AZEVEDO (1998), cerca de 75 milhões de dólares foram gastos com biopesticidas, representando muito pouco em relação aos químicos que em 1991, alcançaram valores de 26,8 bilhões de dólares.

Para aumentar a produção de alimentos utiliza-se da expansão de novas fronteiras agrícolas e do aumento da produtividade, seja pela melhoria do material genético ou pelo aprimoramento das técnicas utilizadas. Este aumento vem provocando problemas, principalmente no aspecto fitossanitário com a incidência crescente de pragas e doenças.

O controle biológico visa manter, através de certas práticas, um equilíbrio no agroecossistema, de modo que o hospedeiro, na presença do patógeno, não sofra danos significativos, em função da ação controladora dos organismos não patogênicos do sistema.

Este trabalho tem como objetivo reunir informações sobre conceitos, agentes, mecanismos de ação de antagonistas e discutir as possibilidades do uso do controle biológico em doenças florestais.

\section{CONCEITO DE CONTROLE BIOLÓGICO}

Doença, numa visão de controle biológico é mais que uma íntima interação patógeno $\mathrm{x}$ hospedeiro $\mathrm{x}$ ambiente. Nesta relação também participam microrganismos não patogênicos, presentes no sítio de infecção, tendo efeitos positivos ou negativos na atividade do patógeno ou do hospedeiro.(COOK \& BAKER, 1983, citado por BETTIOL, 1991a).

O conceito clássico de controle biológico é: "Controle de um microrganismo por outro microrganismo". Outra definição ou um conceito mais amplo proposto por BAKER \& COOK (1974), "é a redução da densidade de inóculo ou das atividades determinantes da doença provocado por um patógeno ou parasita, nos seus estados de atividade ou dormência, por um ou mais organismos, realizado naturalmente ou através da manipulação do 
ambiente, hospedeiro ou antagonista, ou pela introdução em massa de um ou mais antagonistas". Neste sentido, o controle biológico pode ser acompanhado por práticas culturais, para favorecer os antagonistas e a resistência da planta hospedeira ou ambos.

\section{ASPECTOS GERAIS DO CONTROLE BIOLÓGICO}

O controle biológico não se restringe apenas a doenças do filoplano, mas também àquelas da espermosfera, rizosfera e a patógenos pós-colheita.

A microbiolização de sementes pode ser um instrumento eficiente para o controle de patógenos de sementes, principalmente as bactérias, onde o controle químico não é eficiente (LUZ, 1991).

Os microrganismos antagônicos do filoplano consistem basicamente de bactérias, fungos filamentosos e leveduras. No filoplano são intensas as competições por nutrientes, a antibiose, o parasitismo, resultando num controle biológico natural. Segundo LEBEN (1965) citado por BETTIOL (1991b), a microflora epifítica é composta basicamente por microrganismos residentes e transeuntes ou causais. Os microrganismos residentes se multiplicam na superfície foliar sem afetar o hospedeiro. Os transeuntes ou causais estão por acidente. Patógenos de plantas, antes de penetrarem no hospedeiro, comumente são transeuntes do filoplano, sendo neste período expostos às interações com os microrganismos epifíticos (BAKER \& COOK, 1974).

Os microrganismos epifíticos, habitantes das superfícies dos órgãos das plantas, agem como tampão biológico, prevenindo o patógeno de infectar o hospedeiro; por este fato conclui-se que o controle biológico ocorre naturalmente (BETTIOL, 1991b)

O equilíbrio da população microbiana do filoplano pode ser alterado devido à ação de vários fatores tais como: poluição, aplicação de agrotóxicos, fitohormônios e fertilizantes. Portanto, a ocorrência das doenças em plantas sinalizam para um desequilíbrio biológico.

Substâncias químicas utilizadas para proteção de plantas podem induzir o aparecimento ou o aumento da severidade de doenças que são chamadas de iatrogênicas segundo GRIFFITHS (1981), citado por BETTIOL (1991b).

Os exsudatos foliares, assim como materiais depositados sobre as folhas e liberados pelos próprios microrganismos do filoplano, são fontes de nutrientes para os microrganismos epifíticos e saprofíticos do filoplano. O tipo, idade da planta, fatores como luz, temperatura, água de chuva, injúrias, adubação, interferem nos exsudatos foliares. Como materiais depositados destacam-se grãos de pólen, secreção de afídios e restos orgânicos, como principais fontes de nutrientes para os microrganismos epifíticos. 
A aplicação maciça de antagonistas em grande número de locais possíveis de encontrar o patógeno e alterar o ecossistema para favorecer o aumento de antagonistas residentes são estratégias empregadas no controle biológico.

O desenvolvimento dos microrganismos do filoplano é afetado tanto pela qualidade como pela quantidade de nutrientes disponíveis. Efeito marcante de grãos de pólen na população de epífitas foi relatado por NORSE (1972) e WARREN (1972), citados por BETTIOL (1991b).

O controle biológico, diferente do químico, não apresenta efeito imediato e total, e geralmente seu efeito pode estar abaixo do necessário, havendo a necessidade da integração com outros métodos de controle, estabelecendo-se o que se chama de controle integrado.

Algumas lacunas no conhecimento impedem o pleno sucesso do Controle biológico, dentre elas, um melhor entendimento sobre a ecologia do patógeno e do antagonista. Muitos microrganismos quando cultivados em grande escala e sucessivamente, podem perder ou reduzir sua capacidade patogênica, diminuindo a eficiência e a credibilidade do controle. Os fatores edafo-climáticos também têm sido limitantes, pois os antagonistas sofrem com as variações, não exarcebando todo seu potencial quando as condições se afastam do ótimo.

\section{MECANISMOS DE AÇÃO DOS MICRORGANISMOS ANTAGONISTAS}

Os princípios do controle biológico baseiam-se na relação antagônica entre microrganismos, como: predação, competição, amensalismo e parasitismo Muitos microrganismos inibem fitopatógenos por competição por nutrientes, parasitismo direto e pela produção de metabólitos.

O parasitismo parece ser o mecanismo mais eficiente de antagonismo do controle biológico natural, pois os hiperparasitas por viverem às custas do patógeno, estão sujeitos as mesmas variações ambientes e dependem das mesmas condições do organismo parasitado. Dentre os fungos filamentosos, o Trichoderma é reconhecidamente o hiperparasita mais importante e um dos mais estudados.

O ambiente do filoplano é bastante diferente do solo, pois sofre variações mais rápidas e intensas tanto da temperatura como da umidade. Bactérias, leveduras e fungos filamentosos são comumente encontrados em folhas. Como regra geral, no início do desenvolvimento das folhas, as bactérias são as colonizadoras mais freqüentes. Após algumas semanas ocorre um declínio da população bacteriana, pois aumenta a competição por substrato e se inicia o próximo estádio da sucessão microbiológica. À medida que aumenta a 
concentração de açúcares, aumenta a população de leveduras e estas competem por nutrientes disponíveis, reduzindo a população de bactérias.

Inicialmente a folha é pouco colonizada por fungos, contendo esporos dormentes. Quando as folhas entram em senescência, sua resistência é vencida dando origem à colonização de patógenos secundários como Cladosporium spp., Alternaria spp. e Stemphylium spp. Nesta fase há um aumento da atividade de fungos filamentosos saprófitas.

O desenvolvimento de microrganismos na superfície foliar é afetado pela quantidade e pela qualidade dos nutrientes disponíveis no filoplano.

No ambiente da filosfera é grande a competição por nutriente entre bactéria e fungos filamentosos e leveduriformes. $\mathrm{O}$ antagonismo por antibiose é exercido principalmente por bactérias. $\mathrm{O}$ ambiente do solo, embora mais complexo, é mais estável que o ambiente aéreo.

Para que um antagonista seja bem sucedido é preciso que ele tenha capacidade de se multiplicar e colonizar a superfície da planta.

Os microrganismos selecionados do mesmo ambiente onde serão utilizados, tem bastante chance de se adaptarem e de serem eficientes, e neste caso são conhecidos como microrganismos residentes. $\mathrm{O}$ microrganismo estranho, geralmente tem pouca persistência no ambiente, devendo ser reaplicados com mais freqüência.

Fungos patogênicos do solo são mais suscetíveis aos agentes de biocontrole, quando estão na fase saprofítica.

Fungos, bactérias e actinomicetos, alguns com eficiência comprovada, estão sendo comercializados e utilizados regularmente no controle biológico.

BLAKEMAN \& BRODIE (1976) e WELLER (1988), citados por ROBBS (1991) relatam como mecanismos básicos de antagonismo de bactérias o parasitismo direto ou predação, a antibiose, a competição por nutrientes e por sítios e pelo estímulo da resistência do hospedeiro.

Os gêneros de bactérias antagonistas mais prevalentes são as Pseudomonas do grupo fluorescentes (fluorescens putida) e umas poucas não fluorescentes, como P. cepacia, outros gêneros como Bacillus spp. e Strreptomyces spp. e representantes da família Enterobacteriacea. (ROBBS, 1991). 


\section{PRINCIPAIS AGENTES DE CONTROLE BIOLÓGICO}

A seguir são listados e descritos alguns microrganismos utilizados em controle biológico, segundo Mello (1998) \& Robbs (1991):

\section{Ampelomyces quisqualis}

Relatado como razoavelmente eficiente como parasita de espécies de oídio, principalmente em estufas, onde é possível manipular o ambiente, tornando-o mais úmido e com pequena variação de temperatura.

\section{Bacillus spp.}

A espécie mais estudada é o Bacillus subtilis. Este gênero pertence ao grupo das bactérias quimiorganotróficas, gram positivas, cuja característica é a produção de endósporos resistentes ao calor. O maior reservatório de Bacillus é o solo, habitando também ambientes extremos, como desertos e geleiras. Sua ação antagonista não é específica, atuando tanto sobre patógenos foliares, como radiculares. Além de antibióticos, algumas espécies de Bacillus promovem o crescimento de plantas, pela produção de fitohormônios e pela produção de sideróforos.

\section{Gliocladium spp.}

Micoparasita facultativo, habitante natural do solo, tem sido observado parasitando inúmeros fungos como Botrytis spp., Eutypa armeniaceae, Ceratocystis fimbriata, e Fusarium spp. Sutton (1994), citado por Mello (1998), concluiu que a competição por substrato é o principal mecanismo de ação deste antagonista, além da ação de antibiose.

\section{Peniophora gigantea}

É um basidiomiceto comum em madeira e cerne de coníferas, em regiões temperadas. Atuando como invasor primário de ferimentos, competindo por espaço e nutrientes com Heterobasidium (Fomes) annosus, agente da podridão radicular de coníferas. Este é um exemplo clássico de sucesso do controle biológico, com registro aprovado nos E.U.A. pela agencia de proteção ambiental. Aplicado na parte aérea, se difunde por toda a planta e se irradia nas raízes das árvores próximas.

\section{Pseudomonas putida e P. Fluorescens}

São as eubactérias mais estudadas em controle biológico, habitando o solo e também o filoplano. Entretanto, é na rizosfera que são antagonistas eficientes competindo por nutrientes. As Pseudomonas são favorecidas por alta umidade, crescendo numa ampla faixa de temperatura. Além de atuarem como 
antagonistas, também tem ação de promover o crescimento das plantas. Estas são chamadas de Rizobactérias Promotoras de Crescimento de Plantas (RPCP), assim como outros gêneros.

O principal mecanismo de ação deste grupo de bactérias é a produção de metabólitos antibióticos e sideróforos, que são compostos de baixo peso molecular, com a capacidade de aprisionar o $\mathrm{Fe}^{+++}$disponível na rizosfera, e deste modo, podem inibir o desenvolvimento de microrganismos sensíveis à supressão do ferro. Os principais problemas na utilização destas bactérias no controle biológico são a sensibilidade à radiação e a dessecação, no caso de patógenos aéreos. Em doenças radiculares, os problemas estão relacionados principalmente com o $\mathrm{pH}$ do solo.

\section{Streptomyces spp.}

São bactérias gram-positivas, actinomicetales, que formam micélio e esporos. São encontradas em águas, no solo, onde são dominantes, e também colonizam restos de culturas. Produzem de antibióticos, enzimas e inibidores enzimáticos, com aplicação na medicina, agricultura e veterinária. Uma característica destes actinomicetos é a resistência à seca, sendo favorecidos pelo $\mathrm{pH}$ alcalino ou neutro e tolerante às condições de acidez. Um dos problemas no uso destes microrganismos é o difícil isolamento e o crescimento lento em meio de cultura.

\section{Trichoderma spp.}

É um deuteromiceto que produz abundantes conídios em conidióforos que emergem diretamente das hifas. É um fungo de solos orgânicos, vivendo saprofiticamente ou parasitando outros fungos. É um antagonista eficaz no controle de inúmeros fungos fitopatogênicos. Várias espécies tem sido utilizadas em biocontrole, entretanto, Trichoderma harzianum é a espécie mais bem estudada. Elas têm sido utilizadas tanto para patógenos radiculares, como, Rhizoctonia solani, Fusarium spp., Armillaria spp., como da parte aérea, como, Venturia spp., Botrytis spp, etc. O modo de ação é variado, podendo ser por parasitismo, antibiose e competição.

\section{Verticillium lecanii}

É um fungo deuteromiceto apresentando-se como Turribiella sp. na sua forma sexual. É um fungo hiperparasita de ferrugens, requerendo alta umidade relativa $(95-100 \%)$ para seu crescimento sobre as pústulas de ferrugem. Temperaturas entre 15 e $18^{\circ} \mathrm{C}$ são ideais para seu desenvolvimento, bem como, altas intensidades de luz favorecem o parasitismo. Entretanto, o fungo é extremamente sensível à irradiação ultravioleta. Estas características inviabilizam ou dificultam o seu uso como antagonista, pois as condições ambientais do patógeno não são favoráveis às de V. lecanii. Além disso, ele 
apresenta um crescimento micelial muito lento e com baixa produção de conídios em meio de cultura.

Efeitos adversos possíveis atribuídos ao uso de agentes microbianos de controle são alergenicidade, toxicidade, perda de efetividade, patogenicidade e deslocamento competitivo.

\section{SELEÇÃO DE MICRORGANISMOS ANTAGONISTAS}

Os testes de seleção de microrganismos com potencial antagonista podem ser realizados in vitro e in vivo. Neste caso, em condições controladas ou em condições naturais. Ambos os métodos são complementares. Os métodos in vitro, além de serem práticos, servem como uma seleção preliminar para avaliar a capacidade antagonista, e também indicam o comportamento do microrganismo, com relação à sua capacidade de adaptação, crescimento, reprodução, in vitro. Existem algumas restrições com a realização apenas destes testes para a seleção, pois, na maioria das vezes, os resultados positivos obtidos in vitro, ou em condições controladas, não coincidem ou, às vezes, são opostos àqueles obtidos in vivo.

Os principais métodos de seleção de microrganismos in vitro descritos são: pareamento de culturas, papel celofane, placa sobreposta, camada dupla, líquido metabólico, entre outros (MARIANO,1993).

A seleção de microrganismo in vivo é realizada através da aplicação do antagonista, seguida da inoculação do patógeno no hospedeiro por meio de pulverização de suspensão de células, imersão de raízes, ferimentos, dentre outros.

\section{CONTROLE BIOLÓGICO EM FLORESTAS}

Nas três últimas décadas, o aumento do uso de químicos tóxico, encorajou a utilização de estratégias alternativas para proteger a madeira da biodegradação. O controle biológico de fungos decompositores de madeira, foi primeiramente proposto por J. RISBETH em 1963, que aplicou Phanerochaete gigantea para prevenir a colonização de Heterobasidium em tocos recém podados. (CANESSA \& MORRELL, 1997).

$\mathrm{O}$ mecanismo pelo qual os agentes de biocontrole protetores de fungos de madeira atuam, são pouco conhecidos. Um grande número de antagonistas produz quitinase e protease. Os autores estudaram os níveis destas enzimas, infectando Pinus ponderosa com Trichoderma harzianum e constataram que estas enzimas parecem não desempenhar um papel importante na proteção contra os fungos manchadores.(LUI \& MORRELL, 1997).

$\mathrm{O}$ efeito de ectomicorrizas na proteção de raízes de árvores, contra o ataque de patógenos deve ser considerado como uma possibilidade no controle 
biológico. AUER \& KRUGNER (1991) descrevem dois tipos de ação das ectomicorrizas sobre o patógeno: direta e indireta. A primeira está relacionada com a presença do manto micorrízico, que atua como uma barreira física, impedindo a instalação de patógenos na raiz. A ação indireta diz respeito à competição por nutrientes como carboidratos e outras substâncias exsudadas pelas raízes e também ao consumo dos exsudados que reduz a atratividade dos patógenos. Os autores relatam o potencial dos fungos micorrízicos como bioprotetores, principalmente de tombamentos e de doenças radiculares. Entretanto, alguns trabalhos discutem a influencia das micorrizas em patógenos aéreos.

Com relação a antagonistas micorrízicos vesículo-arbusculares, ZAMBOLIM (1991) relata evidências encontradas nas mais variadas espécies de plantas e patógeno, sobre plantas hospedeiras. Para que haja sucesso no controle biológico é necessário que o fungo micorrízico se estabeleça no tecido do hospedeiro, antes que o fungo ou nematóide patogênico ataquem o sistema radicular. Segundo o autor, torna-se difícil estabelecer qual o mecanismo específico de ação destes organismos, entretanto, os principais mecanismos de controle biológico são primeiramente a formação de uma barreira física nas raízes, produção de metabólitos (enzimas, antibióticos, aminoácidos e açucares) e alterações anátomo-morfológicas nas raízes.

CHAPMAN \& XIAO (2000) parearam Hypholoma fasciculare com Armillaria ostoye, em laboratório e no campo. Foi confirmada, em laboratório, a habilidade antagonista de $H$. fasciculare. Os autores observaram que $H$. fasciculare coloniza amplamente as raízes de árvores, prevenindo a invasão do patógeno nas raízes.

BETTIOL et al, (1988), testando vários isolados de Bacillus sp., em

folhas destacadas de Eucalyptus grandis e E. urophylla, contra Cylindrocladium scoparium, obtiveram controle semelhante ao controle químico, quando o tratamento com o antagonista foi feito antes da inoculação com o patógeno.

\section{CONSIDERAÇÕES FINAIS}

Em função dos conhecimentos disponíveis, verifica-se que algumas práticas de controle biológico podem ser utilizadas na área florestal, basicamente em duas situações: no viveiro e/ou em condições controladas e no campo. No viveiro, onde as variações climáticas podem, até certo ponto, serem manipuladas, criando condições para favorecer o antagonista e a planta. Nestas condições, pode-se realizar o tratamento do substrato com agentes microbianos, com o objetivo de controlar os patógenos responsáveis pelo tombamento de mudas e também favorecer o desenvolvimento das plântulas. $\mathrm{O}$ tratamento de 
patógenos da parte aérea poderá ser realizada pelo uso de antagonistas, com a vantagem de poder melhorar as condições de umidade, insolação, favorecendo o estabelecimento e o desenvolvimento do antagonista.

Em função da demanda cada vez maior de tecnologias ambientalmente corretas ou que levem à mitigação dos impactos ambientais, abriu-se um enorme espaço para o controle biológico. Um outro fator muito importante a considerar é que, atualmente muitos dos agroquímicos utilizados em viveiros florestais e até mesmo em plantios, não são registrados no Ministério da Agricultura, portanto, não poderiam estar sendo utilizados. Sendo assim, o desenvolvimento de pesquisas na área de controle biológico é de extrema importância para regularizar esta situação.

A Embrapa Florestas vêm desenvolvendo pesquisas visando o controle biológico de Cylindrocladium spathulatum, fungo patógeno de erva-mate, por meio do uso de antagonistas. Já foram selecionados e testados, em casa de vegetação, alguns microrganismos, com resultados promissores.

\section{BIBLIOGRAFIA CITADA}

AUER, C.G.; KRÜGNER, T.L. Potencial de controle de doenças de plantas com fungos ectomicorrízicos. In: Controle biológico de doenças de plantas. Bettiol,W. (Org.) Jaguariúna: Embrapa-Cnpda, 1991. 338 p. (Embrapa-Cnpda. Documentos, 15).

BAKER, F.K.; COOK, R.J. Biological control of plant pathogens. San Francisco, Freeman and Company, 1974. 433p.

BETTIOL, W. Componentes do controle biológico de doenças de plantas. In: Controle biológico de doenças de plantas. Bettiol,W. (Org.) Jaguariúna: Embrapa-Cnpda, 1991a. 338p. (Embrapa-Cnpda. Documentos, 15).

BETTIOL, W. Controle biológico de doenças do filoplano. In: Controle biológico de doenças de plantas. Bettiol, W. (Org.) Jaguariúna: Embrapa-Cnpda, 1991b. 338p. (Embrapa-Cnpda. Documentos, 15).

BETTIOL, W.; AUER,C.G.; CAMARGO,L.E.A.; KIMATI, H. Controle da mancha foliar de Eucalyptus grandis e E. urophylla induzida por Cylindrocladium scoparium com Bacillus sp. Summa phytopathologica, 14:210-218. 1988.

BETTIOL, W.; GHINI, R. Controle biológico. In: Manual de Fitopatologia. BERGAMIN FILHO, A.; AMORIM, L. e KIMATI, H. (Eds.) $3^{a}$ ed. São Paulo, Ceres, 1995. 919p.

CANESSA, E. A.; MORRELL,J.J. Biological control of wood decay fungi. 
Material und organismen, 31: 167-182. 1997.

CHAPMAN, B.; XIAO, G. Inoculation of stumps with Hypholoma fasciculare as a possible means to control armillaria root disease. Canadian. Journal of Botany, 78:129-134. 2000.

LUI, J.; MORRELL,J.J. Efffect of biocontrol inoculum growth conditions on subsequent chitinase and protease levels in wood exposed to biocontrols and stain fungi. Material und organismen 31:265-279. 1997.

LUZ, W. C. DA. Controle biológico das doenças na espermosfera. In: Controle biológico de doenças de plantas. Bettiol, W. (Org.) Jaguariúna: Embrapa-Cnpda, 1991. 338p. (Embrapa-Cnpda. Documentos, 15).

MARIANO, R. DE R. Métodos de seleção in vitro para o controle microbiológico de patógenos de plantas. In: Revisão anual de patologia de plantas. LUZ, W.C. (Ed.) Passo Fundo, RS, Gráfica Editora Pe. Berthier, 1993. $416 \mathrm{p}$.

MELO, I.S. DE. Agentes microbianos de controle de fungos fitopatogêncos. In: Controle biológico. Vol. I. MELO, I.S. DE e AZEVEDO, J.L. DE. (Eds.) Jaguariúna, SP, Embrapa-CNPMA.1998. 264p.

ROBBS, C. Bactérias como agentes de controle biológico de fitopatógenos. In: Controle biológico de doenças de plantas. Bettiol, W. (Org.) Jaguariúna: Embrapa-Cnpda, 1991. 338p. (Embrapa-Cnpda. Documentos, 15).

ZAMBOLIM, L. Potencial dos fungos micorrízicos vesículo-arbuscular no controle de fitopatógenos e implicações com a nutrição fosfatada. In: Controle biológico de doenças de plantas. Bettiol,W. (Org.) Jaguariúna: Embrapa-Cnpda, 1991. 338p. (Embrapa-Cnpda. Documentos, 15). 